\title{
Graphene Oxide as Support and Regenerative Substrate for Lead lons in Catalytic Conversion of Lactic Acid
}

\author{
Siew Xian Chin,,${ }^{\text {a* }}$ Soon Wei Chook, ${ }^{\text {a }}$ Chin Hua Chia, ${ }^{\mathrm{a}, *}$ Kam Sheng Lau, ${ }^{\mathrm{a}}$ \\ Sarani Zakaria, ${ }^{a}$ and Siti Masrinda Tasirin ${ }^{\mathrm{b}}$ \\ Graphene oxide (GO) was used as a catalyst support and for regeneration \\ of a homogeneous catalyst in the catalytic conversion of glucose to lactic \\ acid (LA). First, a solid base catalyst was prepared through the adsorption \\ of $\mathrm{Pb}^{2+}$ ions by $\mathrm{GO}$ through ionic interaction with oxygenated groups of \\ $\mathrm{GO}$. The collected $\mathrm{GO}-\mathrm{Pb}$ catalyst was characterized, demonstrating the \\ successful loading of $\mathrm{Pb}^{2+}$ onto GO sheets using FTIR and XPS. The GO- \\ $\mathrm{Pb}$ catalyst was subsequently used for the conversion of glucose into LA. \\ A maximum LA yield of approximately $30 \%$ was achieved in $30 \mathrm{~min}$. The \\ catalyst demonstrated the ability to be used for at least five cycles. In \\ contrast, the leached $\mathrm{Pb}^{2+}$ ions during the hydrothermal process were \\ regenerated through adsorption with fresh GO. The regenerated catalyst \\ demonstrated the possibility of the regenerated $\mathrm{Pb}^{2+}$ ions for further \\ catalytic conversions of lactic acid. This study could be essential to \\ produce valuable chemicals through the use of heterogeneous catalysts \\ that are produced via a simple and environmental benign process.
}

Keywords: Adsorptions; Catalyst regeneration; Graphene oxide; Microwave assisted

Contact information: a: Materials Science Program, Faculty of Science and Technology, Universiti Kebangsaan Malaysia, 43600 Bangi, Selangor, Malaysia; b: Department of Chemical and Process Engineering, Universiti Kebangsaan Malaysia, 43600 Bangi, Selangor, Malaysia;

* Corresponding authors: chooksoonwei@gmail.com (S.W. Chook); chia@ukm.edu.my (C.H. Chia)

\section{INTRODUCTIONs}

The dependence on fossil resources for energy and platform chemical production has raised many concerns on its sustainability and its consequences on the environment (Huber et al. 2006). Hence, many efforts have been devoted to search for green, alternative, and sustainable resources. This gradual increased attention has developed into the utilization of lignocellulosic biomass due to their carbon-neutral nature, abundance, availability, and renewability. The conversion of lignocellulosic biomass into fuels, chemicals, and materials has attracted extensive research and commercial interests (Kobayashi et al. 2012). Glucose is one of the main depolymerisation products from cellulose that can be converted into various valuable chemicals (Niu et al. 2015), including 5-hydroxymethyl furfural, furfural, alcohol, methyl levulinate, levulinic acid, formic acid, lactic acid, gluconic acid, etc. (Benoit et al. 2011).

In recent years, lactic acid (LA) production has demonstrated an increasing worldwide demand with a strong market growth of annual production estimated at over 500, 000 tonnes (Jem et al. 2010). Lactic acid is classified and generally recognized as safe (GRAS) to be used as a food additive and has been widely used in both food and non-food industries, such as cosmetic, pharmaceutical, chemical intermediates, metal pickling, and food additives (Datta et al. 1995; Amass et al. 1998). Moreover, LA can also be used as a 
monomer feedstock to produce polylactic acid, which is a biodegradable, biocompatible, and alternative biopolymer to petrochemical-derived polymeric materials (Hofvendahl et al. 1999; Bicker et al. 2005; Mohd Adnan and Tan 2007).

Lactic acid can be produced either via chemical synthesis or microbial fermentation of different carbohydrates such as starch, glucose or xylose (Onda et al. 2008; Wang et al. 2013b; Ghaffar et al. 2014; Lei et al. 2014). Additionally, studies have reported the addition of a small amount of a transition metal ion into a subcritical water system to act as a catalyst enhances the selectivity and conversion of carbohydrate degradation into lactic acid (Bicker et al. 2005). For instance, transition metal ions, such as $\mathrm{Zn}$ (II), Ni (II), Cr (III), $\mathrm{Al}(\mathrm{III})$, and $\mathrm{Pb}$ (II), have been reported for biomass conversion into lactic or levulinic acid (Peng et al. 2010; Wang et al. 2013b; Sitompul et al. 2014). From the previous study (Chin et al. 2016), the utilization of $\mathrm{Pb}^{2+}$ ions was demonstrated as a highly efficient catalyst in the selectivity conversion of lignocellulosic materials into LA.

However, the bottleneck of using a homogeneous metal ion catalysis process is the separation of the metal ions from the system, which requires an additional decontamination process and the reusability of the metal ions catalyst. Therefore, various types of catalysts were developed to improve the selectivity and conversion rate of the production for platform chemicals (Pagliaro and Hutchings 2011). Among them, graphene-based catalysts have attracted an enormous amount of attention as catalyst or catalyst supports (Wang et al. 2013a, 2014; Zhao et al. 2014; Yang et al. 2015b; Zhu et al. 2015; Lv et al. 2016). Graphene oxide (GO) is chemically modified graphene with numerous oxygen functional groups such as hydroxyl, carboxylic, carbonyl, and epoxide groups. The compound GO is frequently used for environmental remediation as an adsorbent for pollutant removal such as cationic dyes (Yang et al. 2011; Chia et al. 2013) and heavy metals (Zhao et al. 2011; Sitko et al. 2013). These studies demonstrated that GO is highly effective in removing these wastewater contaminants through adsorption. The abundance of negatively charged oxygen groups on the large surface area of GO electrostatically attracted and formed strong surface complexes to adsorb and remove the cationic metal ions from aqueous solutions (Yang et al. 2011; Sitko et al. 2013).

This study focused on the utilization of GO acting as a support platform to adsorb $\mathrm{Pb}^{2+}$ ions and how GO could ease the recovery process in the conversion of glucose into LA. Moreover, GO also was used as an adsorbent to study the possibility of the regeneration of the $\mathrm{Pb}$ ions catalyst. The approach not only facilitates the recovery of catalysts from the system, it also opens up the opportunity for further development in the use of nanomaterials for an efficient entrap and release of catalyst, and achieves a synergistic effect to improve catalytic performance of the catalyst in converting glucose into fine chemicals.

\section{EXPERIMENTAL}

\section{Materials}

Analytical grade chemicals, sodium hydroxide, $\mathrm{NaOH}$ (purity $\geq 99 \%$ ) and sulfuric acid, $\mathrm{H}_{2} \mathrm{SO}_{4}$ (purity 95-98\%), levulinic acid (purity $\geq 99.5 \%$ ), potassium permanganate $\left(\mathrm{KMnO}_{4}, 99.9 \%\right)$, hydrogen peroxide $\left(\mathrm{H}_{2} \mathrm{O}_{2}, 30 \%\right)$, and phosphoric acid $\left(\mathrm{H}_{3} \mathrm{PO}_{4}, 85 \%\right)$ were purchased from Merck (Darmstadt, Germany). Lead (II) nitrate (purity $\geq 99 \%$ ), glucose (purity $\geq 99.5 \%$ ), xylose (purity $\geq 99.5 \%$ ), lactic acid (purity $\geq 99.5 \%$ ), 5-HMF (purity $\geq 99.5 \%$ ), acetic acid (purity $49-51 \%$ ), and formic acid ( $\geq 95 \%$ ) were purchased 
from Sigma Aldrich (Shanghai, China). Graphite flakes were purchased from Asbury Graphite Mill, Inc. (Asbury, NJ, USA). All chemicals were used without further purification.

\section{Preparation of $G O$}

The GO was prepared using a simplified Hummer's method (Chook et al. 2015). First, the graphite flake was oxidized to graphite oxide with $\mathrm{H}_{2} \mathrm{SO}_{4}$ and $\mathrm{KMnO}_{4}$ by stirring the mixture for 3 days. To stop the oxidation reaction, $\mathrm{H}_{2} \mathrm{O}_{2}$ was added to the graphite oxide solution, which was followed by centrifugation to remove the excess chemicals. The graphite oxide was repeatedly washed to remove excessive chemicals and then placed in an ultra-sonication bath to obtain exfoliated GO.

Adsorption of $\mathrm{Pb}^{2+}$ ions by $\mathrm{GO}$

Briefly, $10 \mathrm{~mL}$ of $\mathrm{GO}(50 \mathrm{mg})$ was added into a solution containing $0.1 \mathrm{~g}$ of $\mathrm{Pb}\left(\mathrm{NO}_{3}\right)_{2}$ and stirred for $24 \mathrm{~h}$ to allow the $\mathrm{GO}$ to adsorb $\mathrm{Pb}^{2+}$ ions. The resulting mixture was washed by centrifugation to remove the excessive $\mathrm{Pb}^{2+}$ ions. The precipitate was collected and subjected to freeze drying for two days using a freeze dryer (ScanVac CoolSafe, Lynge, Denmark). The GO-Pb catalyst was collected and kept in a dry condition prior to the characterization until further use.

\section{Methods}

Characterizations of $\mathrm{GO}-\mathrm{Pb}$ catalyst

The functional groups of the GO and GO-Pb were characterized using Fourier transform infrared spectroscopy (FTIR, Bruker Alpha, Massachusetts, USA). The morphology and element content of the GO and GO-Pb catalyst were acquired using a field emission scanning electron microscope (FESEM, Zeiss Merlin Compact, Jena, Germany) equipped with an energy dispersive X-ray spectroscope (EDS). An X-ray photoelectron spectroscope (XPS, Kratos Shidmazu, Kyoto, Japan) was used to characterize the GO and $\mathrm{GO}-\mathrm{Pb}$. The amount of $\mathrm{Pb}^{2+}$ ions that was adsorbed and released by $\mathrm{GO}$ and $\mathrm{GO}-\mathrm{Pb}$, respectively were measured using an inductively coupled plasma-optical emission spectroscope (ICP-OES, Perkin-Elmer Optima 4300 DV, Massachusetts, USA).

\section{Conversion of glucose into LA using GO-Pb catalyst}

A microwave reactor (Anton Paar, Monowave 300, Graz, Austria) equipped with a temperature controller with a built-in infrared (IR) sensor to perform the hydrolysis reaction. The GO-Pb catalyst was added into a $30 \mathrm{~mL}$ borosilicate glass vial containing 10 $\mathrm{mL}$ of $1 \mathrm{~g} / \mathrm{L}$ glucose solution, sealed with a snap cap and polytetrafluoroethylene coated silicone septum. The vial was irradiated to $190{ }^{\circ} \mathrm{C}$, held for different reaction times (15 min to $180 \mathrm{~min}$ ) and stirred at $600 \mathrm{rpm}$ under pressurized conditions. After completing the reaction, the temperature was rapidly decreased to $55^{\circ} \mathrm{C}$ within approximately 2 min to 3 min, using compressed air flushing. The hydrolysate was collected for a high-performance liquid chromatography (HPLC) analysis and the catalyst was washed with deionized water to be used in consecutive reaction cycles.

Chemical analyses on the hydrolysate to determine the concentration of sugars (glucose, fructose) and organic acids (lactic, formic, acetic, and levulinic acid) were performed using a HPLC system (Agilent 1260 Infinity Quaternary, California, USA) and a Hi-plex H column with a refractive index (RI) detector. The 5-HMF was measured using an ultraviolet (UV) detector at $280 \mathrm{~nm}$. The measurement was conducted using a mobile 
phase containing $5 \mathrm{mmol} \mathrm{H}_{2} \mathrm{SO}_{4}$ at a flow rate of $0.6 \mathrm{~mL} / \mathrm{min}$ and the temperature of the column and detector was set at $60{ }^{\circ} \mathrm{C}$ and $55{ }^{\circ} \mathrm{C}$, respectively. All experiments were conducted in duplicate and a mean value was reported. The yield of LA was calculated according to Eq. 1.

$$
\text { Yield of LA }(\%)=\frac{\text { Mole of LA produced }}{2\left(\text { mole of } \mathrm{C}_{6} \text { units }\right)} \times 100
$$

\section{RESULTS AND DISCUSSION}

\section{Characterization of GO-Pb}

The FTIR spectra of the GO and GO-Pb are shown in Fig. 1(a). The results suggested that GO exhibited typical various oxygenated moiety groups, such as hydroxyl, carbonyl, carboxylic, and epoxy, that correspond to the peak at $1720 \mathrm{~cm}^{-1}, 1360 \mathrm{~cm}^{-1}, 1241$ $\mathrm{cm}^{-1}, 1043 \mathrm{~cm}^{-1}$, and $973 \mathrm{~cm}^{-1}$, respectively (Mondal et al. 2014; He et al. 2015).
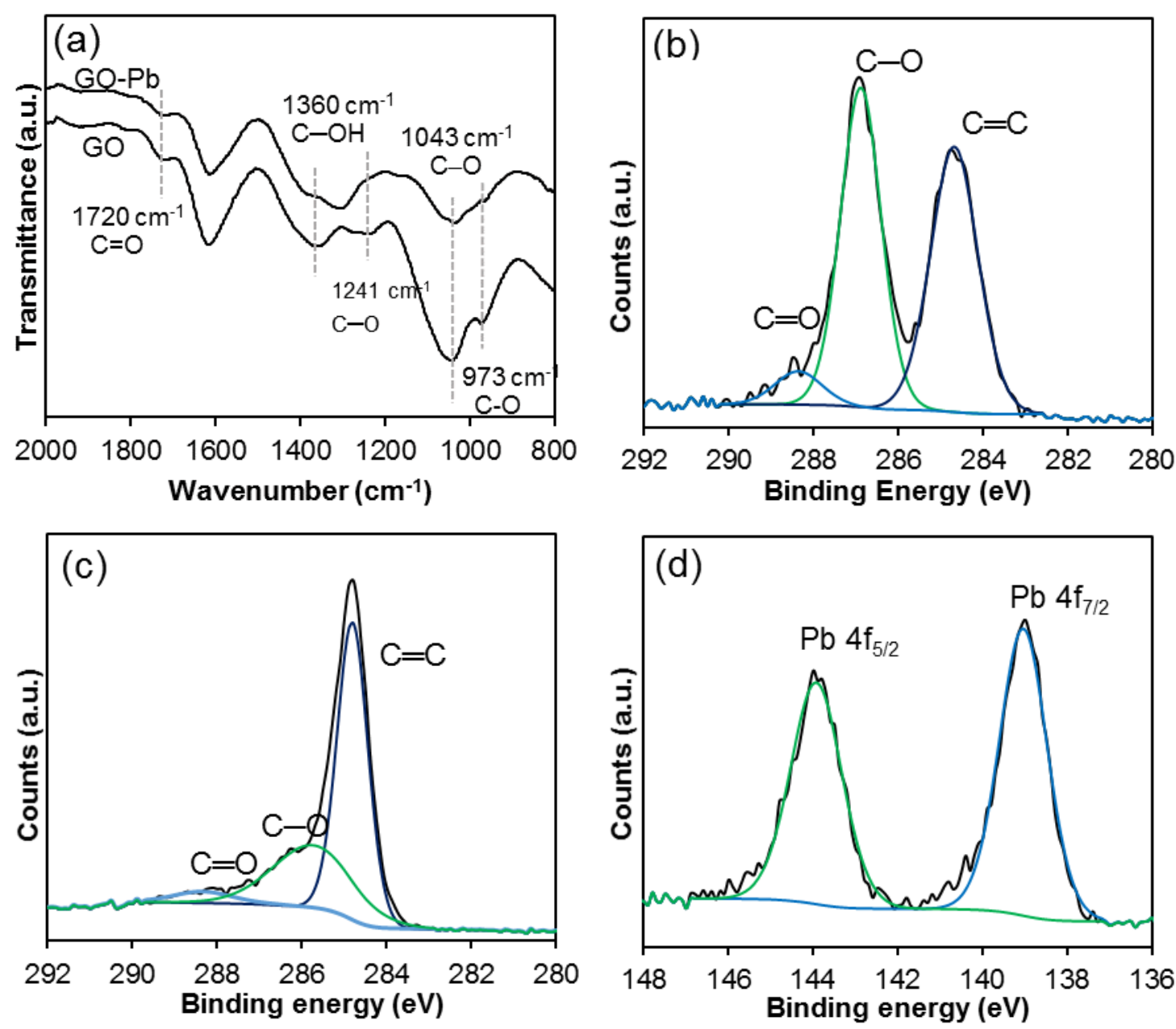

Fig. 1. (a) IR spectrum of $G O$ and $G O-P b$, (b) high resolution $C 1 s$ XPS spectrum of $G O$, (c) high resolution $\mathrm{C} 1 \mathrm{~s}$ XPS spectrum of $\mathrm{GO}-\mathrm{Pb}$, and (d) high resolution Pb4f XPS spectrum of $\mathrm{GO}-\mathrm{Pb}$ 
The oxygen functional groups were weakened and diminished after the adsorption of $\mathrm{Pb}^{2+}$ ions. For instance, the peaks at $1360 \mathrm{~cm}^{-1}, 1241 \mathrm{~cm}^{-1}$, and $973 \mathrm{~cm}^{-1}$ assigned to the $\mathrm{C}-\mathrm{O}, \mathrm{C}-\mathrm{OH}$, and $\mathrm{C}-\mathrm{O}$, respectively, were diminished after the adsorption of the $\mathrm{Pb}^{2+}$ ions. Meanwhile, the intensity for the bands at $1720 \mathrm{~cm}^{-1}$ and $1043 \mathrm{~cm}^{-1}$ that corresponded to $\mathrm{C}=\mathrm{O}$ and $\mathrm{C}-\mathrm{O}$, respectively, for $\mathrm{GO}-\mathrm{Pb}$ were found weak compared to $\mathrm{GO}$. This was due to the occupied oxygen groups by the adsorbed $\mathrm{Pb}^{2+}$ ion, which also contributed to the weaker dispersion of GO-Pb in the water. Therefore, to verify this, a high-resolution XPS spectra of $\mathrm{GO}$ and $\mathrm{GO}-\mathrm{Pb}$ were acquired and presented in Fig. 1(b through d). The $\mathrm{C} 1 \mathrm{~s}$ of $\mathrm{GO}$ is presented in Fig. 1(b), where the peaks assigned to the sp2 hybridization of carbon $(\mathrm{C}=\mathrm{C}, 284.8 \mathrm{eV})$, epoxy or hydroxyl $(\mathrm{C}-\mathrm{O}, 287.0 \mathrm{eV})$, and carbonyl $(\mathrm{C}=\mathrm{O}, 288.3 \mathrm{eV})$ were identified (Marcano et al. 2010). Upon the adsorption of $\mathrm{Pb}^{2+}$ ions, the peaks that corresponded to $\mathrm{C}-\mathrm{O}$ and $\mathrm{C}=\mathrm{O}$ of $\mathrm{GO}-\mathrm{Pb}$ (Fig. 1c) were much weaker compared to the GO. This result collaborated with the FTIR results, in which these functional groups were occupied by $\mathrm{Pb}^{2+}$ ions on the surface of the GO sheets. Figure 1(d) demonstrated the presence of $\mathrm{Pb}^{2+}$ ions on the GO-Pb samples. Moreover, the EDX results confirmed the $\mathrm{GO}-\mathrm{Pb}$ catalyst contained $16.4 \mathrm{wt} \% \mathrm{~Pb}^{2+}$ ions. The ICP-OES results indicated that the GO$\mathrm{Pb}$ catalyst consisted of $334 \mathrm{mg} / \mathrm{g}$ of $\mathrm{Pb}^{2+}$ ions.

\section{Catalytic Conversion of LA from Glucose}

The reaction was conducted in a microwave reactor, where the microwave irradiation provided a rapid and homogeneous heating due to high efficient energy adsorption as compared to conventional heating (Chin et al. 2014). The effects of using $\mathrm{GO}-\mathrm{Pb}$ as the catalyst for the conversion of glucose into LA was conducted at $190{ }^{\circ} \mathrm{C}$ for 30 min, and the results are shown in Fig. 2.

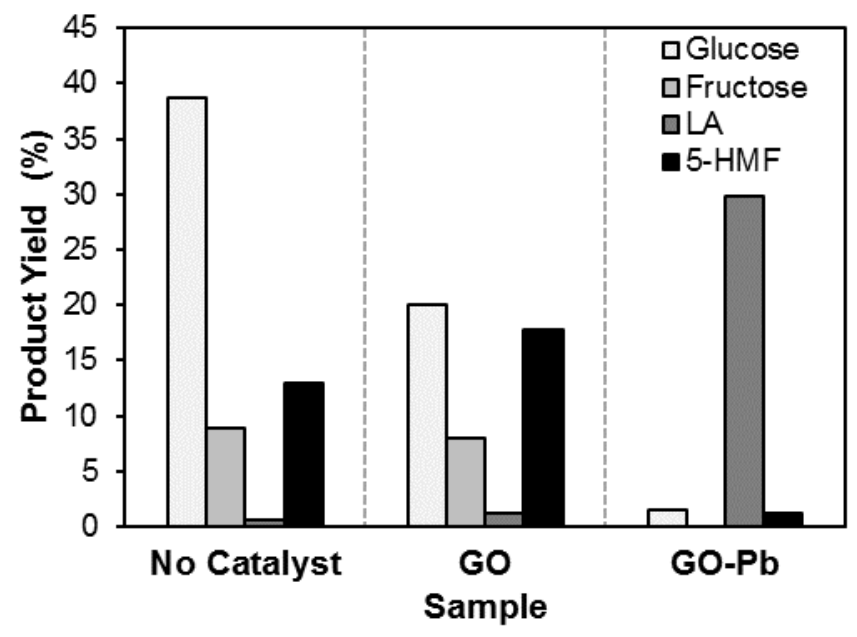

Fig. 2. Conversion of glucose and products yield in the condition of with and without catalyst

As depicted in Fig. 2, the degradation rate of glucose without any catalyst was low, i.e., $38.7 \%$ of the glucose remained, with a relatively lower conversion yield of fructose $(9.0 \%)$, LA (0.7\%), and 5-HMF (13.0\%). Meanwhile, when GO was used as the catalyst, the degradation rate of the glucose increased, where $20 \%$ of the glucose remained in the hydrolysate. Additionally, the formation of 5-HMF was more favourable with a higher yield of 5-HMF (17.7\%) and lower yield of LA (1.2\%) when GO was used as the catalyst. This is because the GO enhanced the dehydration rate of glucose to 5-HMF (Mondal et al. 
2014; Wang et al. 2014; Yang et al. 2015b). In contrast, the degradation of glucose using the GO-Pb catalyst showed a marked increase with a remainder of $1.5 \%$ of glucose, while the yield of LA notably increased to $30 \%$ and a low amount of 5-HMF (1.2\%) was detected. The presence of $\mathrm{Pb}^{2+}$ ions has been shown to be favourable for the conversion of LA compared to HMF or levulinic acid (Chin et al. 2016). In addition, a trace amount of formic acid, acetic acid, and glycolic acid was produced after the hydrothermal reaction due to the oxidation of glucose (Jin et al. 2008; Yang et al. 2015a). Additionally, activated carbon (AC) was also used as $\mathrm{Pb}^{2+}$ ions catalyst support, where the obtained catalyst $(\mathrm{AC}-\mathrm{Pb})$ exhibited a much lower conversion rate of 5.6\% LA than GO-Pb (results not shown). This could be attributed to the low $\mathrm{Pb}^{2+}$ loading of $\mathrm{AC}$ than $\mathrm{GO}$.

The performance of the GO-Pb catalyst was further evaluated by the varied catalyst amounts, reaction time, and recyclability. Firstly, different amounts of GO-Pb catalyst were used to study the effects on the conversion of glucose into LA (Fig. 3). The degradation of glucose gradually increased as the GO-Pb increased. The yield of LA increased from $22.9 \%$ to $29.8 \%$ as the GO-Pb was increased from $10 \mathrm{mg}$ to $50 \mathrm{mg}$. However, $100 \mathrm{mg} \mathrm{GO}-\mathrm{Pb}$ had a lower yield of LA to $21.7 \%$ with a higher amount of acetic acid $(0.12 \mathrm{~g} / \mathrm{L})$ as compared to $0.05 \mathrm{~g} / \mathrm{L}$ for $50 \mathrm{mg} \mathrm{GO}-\mathrm{Pb}$. This was attributed to further oxidative degradation of $\mathrm{LA}$ to acetic acid that was catalyzed by the $\mathrm{Pb}^{2+}$. The $\mathrm{Pb}^{2+}$ ions catalyzed conversion began with glucose isomerization to fructose and further underwent retro-aldol fragmentation to produce dihydroxyacetone and glyceraldehyde. These two triose fragments were transformed into LA via dehydration and 1,2-hydride shift reactions (Wang et al. 2013b), and LA is finally oxidized to acetic acid (Chin et al. 2016). Other organic acids, such as formic acid and glycolic acid, were detected after the reaction. This may be due to the rupture of glucose or LA that further degraded into formic acid and other byproducts. (Zargari et al. 2015). Therefore, in this case, the obtained results suggested that excessive $\mathrm{GO}-\mathrm{Pb}$ led to the oxidation of LA into other degradation products.

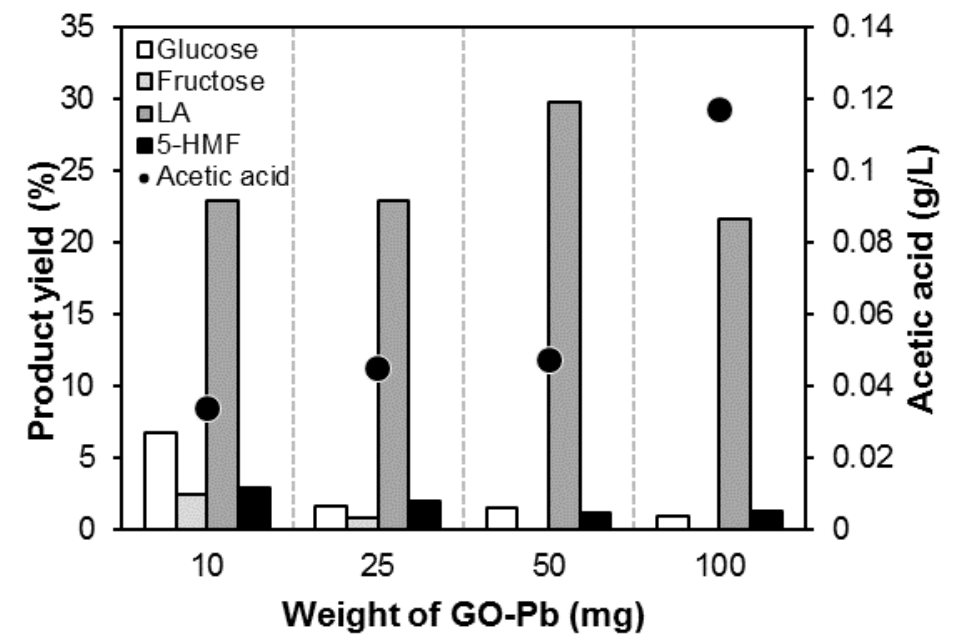

Fig. 3. Effects of GO-Pb amount on the conversion of glucose to LA

The yield of LA under various reaction times was also studied, ranging from 15 min to $120 \mathrm{~min}$ and is presented in Fig. 4. The yield of LA gradually increased from $27.9 \%$ to $29.8 \%$ as the reaction was extended from $15 \mathrm{~min}$ to $30 \mathrm{~min}$. Moreover, as the reaction time from $30 \mathrm{~min}$ to $120 \mathrm{~min}$, the yield of LA gradually decreased while the yield of acetic acid increased. 
The yield of acetic acid increased from $0.03 \mathrm{~g} / \mathrm{L}$ to $0.07 \mathrm{~g} / \mathrm{L}$ as the reaction time increased from $15 \mathrm{~min}$ to $180 \mathrm{~min}$. This suggested that longer reaction time favored further degradation of products into acetic acid as the similar finding was reported in our previous study (Chin et al. 2016).

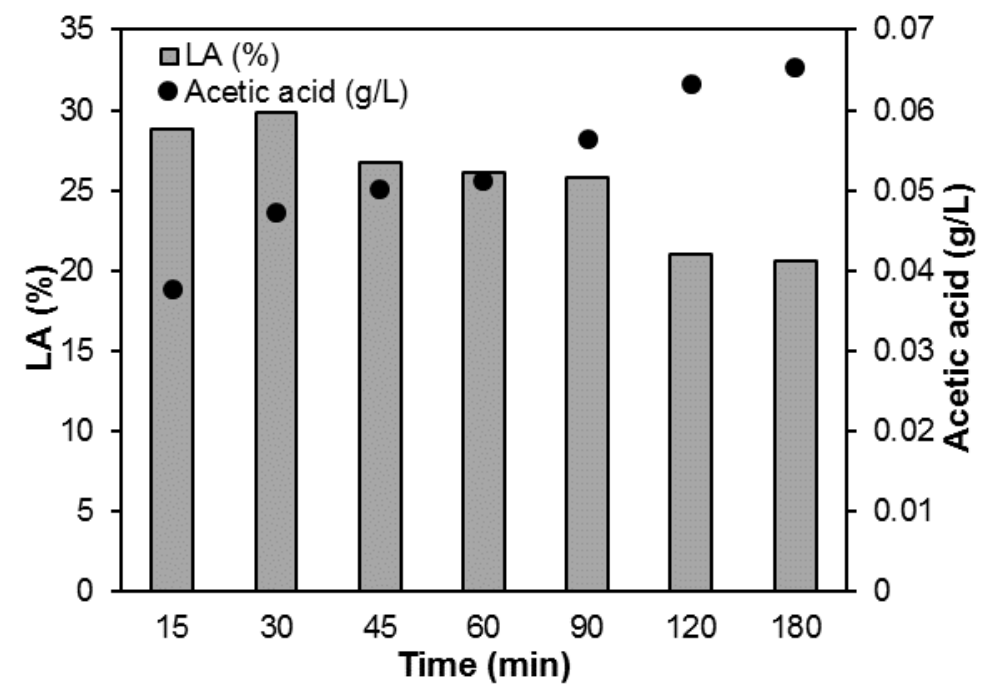

Fig. 4. Effects of reaction time on the conversion of glucose into LA

The recyclability of the GO-Pb was studied, and the results are depicted in Fig. 5. The GO-Pb catalyst was collected via filtration and washed using deionized water after the first cycle reaction. Then, the catalyst was used for another 5 cycles of conversion reaction for $30 \mathrm{~min}$ and $60 \mathrm{~min}$, respectively. Generally, the yield for LA demonstrated a decreasing trend during each cycle.

The highest yield of LA and acetic acid was achieved at the 1st cycle of the reaction, which were both conducted at $30 \mathrm{~min}$. However, both yields dropped and remained at a certain range for the following 5 cycles. As shown in Fig. 5, the GO-Pb had a conversion yield of $29 \%$ and the yield for 2 nd cycle decreased to $15.6 \%$ for the 30 min run. This could have been due to the presence of a lesser amount of $\mathrm{Pb}^{2+}$ ions as the GO deoxygenation occurred at $190{ }^{\circ} \mathrm{C}$ on the first cycle, which was attributed to the leaching of $\mathrm{Pb}^{2+}$ ions.
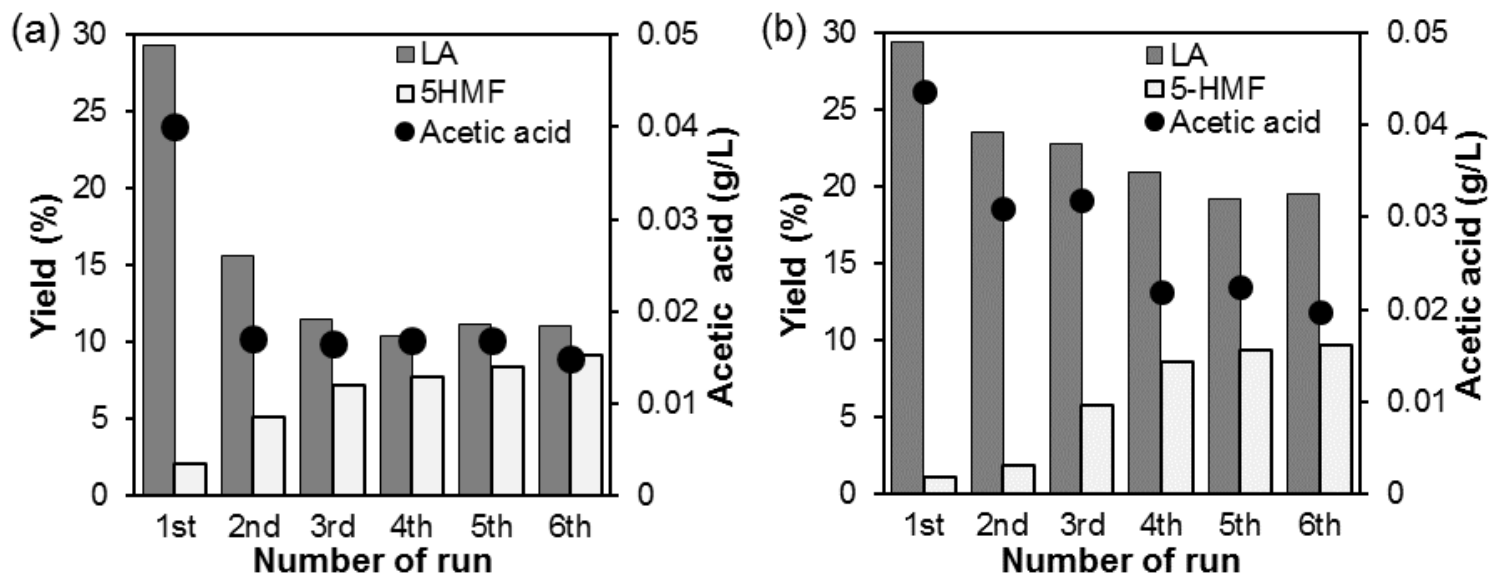

Fig. 5. Recyclability for GO-Pb for (a) $30 \mathrm{~min}$ and (b) $60 \mathrm{~min}$ 
The results (Fig. 5b) indicated that a relatively higher yield of LA was obtained for the 5 cycles following the $1^{\text {st }}$ cycle $\left(2^{\text {nd }}\right.$ through $\left.6^{\text {th }}\right)$ at a longer reaction time of 60 min. Meanwhile, the yield of 5-HMF gradually increased over the cycles. This is attributed to the decreased selectivity conversion of LA from glucose, in turn favouring the conversion into 5-HMF (Mondal et al. 2014). The autohydrolysis occurred in water at high temperatures, where the formation of $\mathrm{H}_{3} \mathrm{O}^{+}$to catalyse the dehydration of glucose into 5HMF (Hoekman et al. 2011).

The effectiveness of the GO-Pb catalyst in the conversion of lignocellulosic material into LA was verified by using microcrystalline cellulose (MCC) as the model compound instead of glucose. The reaction was conducted at $190{ }^{\circ} \mathrm{C}$ for $2 \mathrm{~h}$. As depicted in Fig. 6, similar results were observed in comparison with Fig. 1, in which the addition of GO enhanced the rate of degradation of MCC into glucose and obtained a higher yield of 5-HMF and levulinic acid as compared to the reaction without the catalyst. Meanwhile, $\mathrm{GO}-\mathrm{Pb}$ catalyst gave the highest yield of LA of approximately $15 \%$.

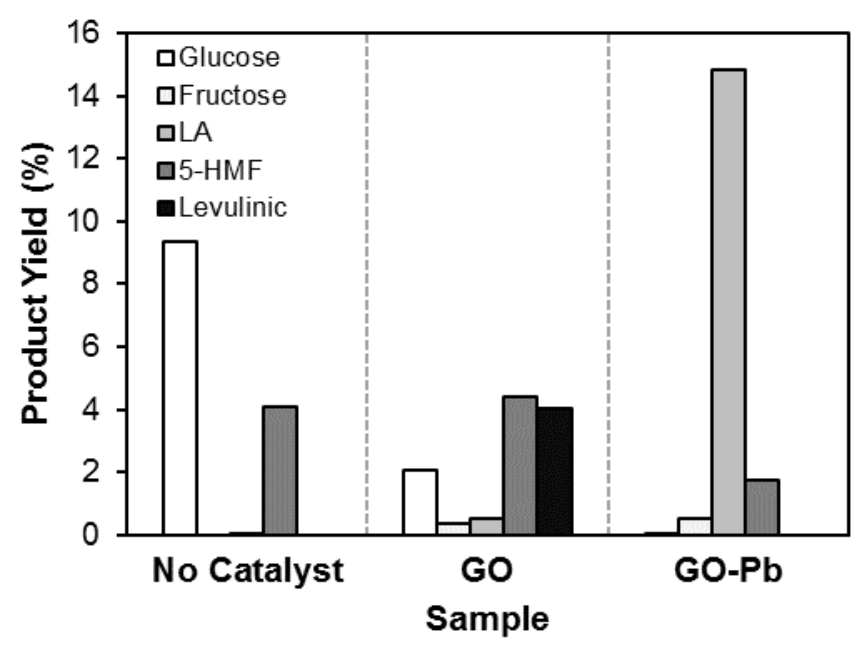

Fig. 6. Conversion of MCC and product yield in the condition of with and without catalyst

\section{Regeneration of $\mathrm{Pb}^{2+}$ Ions for LA Conversion}

As previously discussed, the leach of $\mathrm{Pb}^{2+}$ from the $\mathrm{GO}-\mathrm{Pb}$ was inevitability due to the deoxygenation of $\mathrm{GO}$ at high temperatures. Regeneration of the $\mathrm{Pb}^{2+}$ ions was performed by the attempted adsorption by fresh GO. After a typical hydrothermal reaction (50 mg GO-Pb, $190{ }^{\circ} \mathrm{C}, 30 \mathrm{~min}$ ), $25 \mathrm{mg}$ of fresh GO was added into the hydrolysate and stirred for $24 \mathrm{~h}$ to facilitate the adsorption of $\mathrm{Pb}^{2+}$ ions. The regenerated catalyst (labelled as $\mathrm{R}-\mathrm{GO}-\mathrm{Pb}$ ) was collected from the hydrolysate and followed by the freeze dried process. Meanwhile, the measurement of hydrolysate using ICP-OES indicated that approximately $84.6 \%$ of $\mathrm{Pb}^{2+}$ ions were successfully regenerated using the GO. 
Table 1. Concentration of Compound in Hydrolysate after the Hydrothermal Reaction with $\mathrm{GO}-\mathrm{Pb}$ and $\mathrm{R}-\mathrm{GO}-\mathrm{Pb}$

\begin{tabular}{|c|c|c|c|c|}
\hline Hydrolysate & Glucose (\%) & LA (\%) & 5-HMF (\%) & Acetic Acid (g/L) \\
\hline GO-Pb & 1.46 & 29.8 & 1.19 & 0.047 \\
\hline GO-Pb* & 1.46 & 29.3 & 1.15 & 0.044 \\
\hline R-GO-Pb & 1.07 & 17.3 & 0.77 & 0.029 \\
\hline *After GO adsorptions of $\mathrm{Pb}^{2+}$ ions \\
\hline
\end{tabular}

All of the hydrolysates were analyzed using HPLC, and the results are summarized in Table 1. The compounds in the first hydrothermal reaction using GO-Pb contained similar amounts of a hydrolysate compound after GO adsorption, which suggested that there was no interaction between GO and the hydrolysate compounds. In contrast, the hydrolysate obtained using R-GO-Pb consisted of $17.3 \%$ lactic acid with a low yield of 5HMF. The proposed method of using GO as an adsorbent for the regeneration of catalyst ions and to reuse the catalyst for a further conversion process also offered a solution to prevent the wastage of the $\mathrm{Pb}^{2+}$ ions and environmental concerns.

\section{CONCLUSIONS}

1. This study demonstrated the utilization of GO as a supporting substrate for $\mathrm{Pb}^{2+}$ ions through strong adsorptions capability, which was shown by the XPS characterization. Moreover, GO also was used to regenerate the catalyst ions after the catalytic conversion.

2. As a catalyst support, the $\mathrm{GO}$ adsorbed $\mathrm{Pb}^{2+}$ ions through electrostatic interactions. The $\mathrm{GO}-\mathrm{Pb}$ demonstrated that more than a $30 \%$ yield can be achieved as well as the capability for several cycles of regeneration.

3. Moreover, $\mathrm{GO}$ can regenerate the leached $\mathrm{Pb}^{2+}$ ions in the hydrolysate without greatly affecting the amount of LA and other compounds. The regenerated catalyst demonstrated a high possibility of reusing the $\mathrm{Pb}^{2+}$ ions catalyst with ease.

\section{ACKNOWLEDGEMENTS}

The authors acknowledge the financial support provided by the research project grants of DIP-2015-009 and FRGS/1/2016/STG01/UKM/02/3.

\section{REFERENCES CITED}

Amass, W., Amass, A., and Tighe, B. (1998). "A review of biodegradable polymers: Uses, current developments in the synthesis and characterization of biodegradable polyesters, blends of biodegradable polymers and recent advances in biodegradation studies," Polym. Int. 47(2), 89-144. DOI: 10.1002/(SICI)1097-

0126(1998100)47:2<89::AID-PI86>3.0.CO;2-F 
Benoit, M., Rodrigues, A., Zhang, Q., Fourré, E., de Oliveira Vigier, K., Tatibouët, J.-M., and Jérôme, F. (2011). "Depolymerization of cellulose assisted by a nonthermal atmospheric plasma,” Angew. Chem. Int. Edit. 50(38), 8964-8967. DOI: 10.1002/anie.20110412

Bicker, M., Endres, S., Ott, L., and Vogel, H. (2005). "Catalytical conversion of carbohydrates in subcritical water: A new chemical process for lactic acid production," J. Mol. Catal. A- Chem. 239(1-2), 151-157. DOI: 10.1016/j.molcata.2005.06.017

Chia, C. H., Razali, N. F., Sajab, M. S., Zakaria, S., Huang, N. M., and Lim, H. N. (2013). "Methylene blue adsorption on graphene oxide," Sains Malaysiana 42(6), 819-826.

Chin, S. X., Chia, C. H., Fang, Z., Zakaria, S., Li, X. K., and Zhang, F. (2014). “A kinetic study on acid hydrolysis of oil palm empty fruit bunch fibers using a microwave reactor system," Energ. Fuel. 28(4), 2589-2597. DOI: 10.1021/ef402468z

Chin, S. X., Tasirin, S. M., Chan, C. H., Chia, C. H., Chook, S. W., Zakaria, S., and Sajab, M. S. (2016). "Catalytic conversion of empty fruit bunch (EFB) fibres into lactic acid by lead (II) ions," BioResources 11(1), 21860-2201. DOI: 10.15376/biores.11.1.26263-26268

Chook, S. W., Chia, C. H., Zakaria, S., Ayob, M. K., Ming, H. N., Neoh, H. M., and Jamal, R. (2015). "Antibacterial hybrid cellulose-graphene oxide nanocomposite immobilized with silver nanoparticles," RSC Advance 5, 26263-26268. DOI: 10.1039/C5RA01897H

Datta, R., Tsai, S.-P., Bonsignore, P., Moon, S.-H., and Frank, J. R. (1995). "Technological and economic potential of poly(lactic acid) and lactic acid derivatives," FEMS Microbiol. Rev. 16(2-3), 221-231. DOI: 10.1016/01686445(94)00055-4

Ghaffar, T., Irshad, M., Anwar, Z., Aqil, T., Zulifqar, Z., Tariq, A., Kamran, M., Ehsan, N., and Mehmood, S. (2014). "Recent trends in lactic acid biotechnology: A brief review on production to purification," J. Radiat. Res. Appl. Sci. 7(2), 222-229. DOI: 10.1016/j.jrras.2014.03.002

He, D., Peng, Z., Gong, W., Luo,Y., Zhao, P., and Kong L. (2015). "Mechanism of a green graphene oxide reduction with reusable potassium carbonate," RSC Advance 5, 11966-11972. DOI: 10.1039/c4ra14511a

Hoekman, S. K., Broch, A., and Robbins, C. (2011). "Hydrothermal carbonization (HTC) of lignocellulosic biomass," Energ. Fuel. 25(4), 1802-1810. DOI: 10.1021/ef101745n

Hofvendahl, K., Åkerberg, C., Zacchi, G., and Hahn-Hägerdal, B. (1999). "Simultaneous enzymatic wheat starch saccharification and fermentation to lactic acid by Lactococcus lactis," Appl. Microbiol. Biot. 52(2), 163-169. DOI: $10.1007 / \mathrm{s} 002530051503$

Huber, G. W., Iborra, S., and Corma, A. (2006). "Synthesis of transportation fuels from biomass: Chemistry, catalysts, and engineering," Chem. Rev. 106(9), 4044-4098. DOI: $10.1021 / \mathrm{cr} 068360 \mathrm{~d}$

Jem, K. J., Van der Pol, J., and de Vos, S. (2010). "Microbial lactic acid, its polymer poly(lactic acid), and their industrial applications," in: Plastics from Bacteria, G. G.Q. Chen, (ed.), Springer Berlin, Heidelberg, pp. 323-346. DOI: 10.1007/978-3-64203287-5_13 
Jin, F., Yun, J., Li, G., Kishita, A., Tohji, K., and Enomoto, H. (2008). "Hydrothermal conversion of carbohydrate biomass into formic acid at mild temperatures," Green Chem. 10(6), 612-615. DOI: 10.1039/B802076K

Kobayashi, H., Ohta, H., and Fukuoka, A. (2012). "Conversion of lignocellulose into renewable chemicals by heterogeneous catalysis," Catal. Sci. Technol. 2(5), 869-883. DOI: $10.1039 / \mathrm{C} 2 \mathrm{CY} 00500 \mathrm{~J}$

Lei, X., Wang, F.-F., Liu, C.-L., Yang, R.-Z., and Dong, W.-S. (2014). “One-pot catalytic conversion of carbohydrate biomass to lactic acid using an $\mathrm{ErCl}_{3}$ catalyst," Appl. Catal. A-Gen. 482, 78-83. DOI: 10.1016/j.apcata.2014.05.029

Lv, G., Wang, H., Yang, Y., Deng, T., Chen, C., Zhu, Y., and Hou, X. (2016). "Direct synthesis of 2,5-diformylfuran from fructose with graphene oxide as a bifunctional and metal-free catalyst," Green Chem. 18(8), 2302-2307. DOI: 10.1039/C5GC02794B

Marcano, D. C., Kosynkin, D. V., Berlin, J. M., Sinitskii, A., Sun, Z., Slesarev, A., Alemany, L. B., Lu, W., and Tour, J. M. (2010). "Improved synthesis of graphene oxide," ACS Nano 4(8), 4806-4814. DOI: 10.1021/nn1006368

Mohd Adnan, A. F., and Tan, I. K. P. (2007). "Isolation of lactic acid bacteria from Malaysian foods and assessment of the isolates for industrial potential," Bioresource Technol. 98(7), 1380-1385. DOI: 10.1016/j.biortech.2006.05.034

Mondal, D., Chaudhary, J. P., Sharma, M., and Prasad, K. (2014). "Simultaneous dehydration of biomass-derived sugars to 5-hydroxymethyl furfural (HMF) and reduction of graphene oxide in ethyl lactate: One pot dual chemistry," RSC Advance 4(56), 29834-29839. DOI: 10.1039/C4RA05049E

Niu, M., Hou, Y., Ren, S., Wang, W., Zheng, Q., and Wu, W. (2015). “The relationship between oxidation and hydrolysis in the conversion of cellulose in $\mathrm{NaVO}_{3}-\mathrm{H}_{2} \mathrm{SO}_{4}$ aqueous solution with $\mathrm{O}_{2}$," Green Chem. 17(1), 335-342. DOI: 10.1039/C4GC00970C

Onda, A., Ochi, T., Kajiyoshi, K., and Yanagisawa, K. (2008). "A new chemical process for catalytic conversion of d-glucose into lactic acid and gluconic acid," Appl. Catal. A-Gen. 343(1-2), 49-54. DOI: 10.1016/j.apcata.2008.03.017

Pagliaro, M., and Hutchings, G. J. (2011). "Heterogeneous catalysis for fine chemicals," Catal. Sci. Technol. 1(9), 1543-1543. DOI: 10.1039/C1CY90035H

Peng, L., Lin, L., Zhang, J., Zhuang, J., Zhang, B., and Gong, Y. (2010). "Catalytic conversion of cellulose to levulinic acid by metal chlorides," Molecules 15(8), 52585272. DOI: $10.3390 /$ molecules 15085258

Sitko, R., Turek, E., Zawisza, B., Malicka, E., Talik, E., Heimann, J., Gagor, A., Feist, B., and Wrzalik, R. (2013). "Adsorption of divalent metal ions from aqueous solutions using graphene oxide," Dalton Transaction 42(16), 5682-5689. DOI: 10.1039/C3DT33097D

Sitompul, J. P., Simangunsong, R. F., Asrizal, A. A., Alisyahbana, H., Lee, H. W., and Rasrendra, C. B. (2014). "Catalytic conversion of empty fruit bunch of palm oil for producing lactic acid," Procedia Cheistry 9, 88-93. DOI:

10.1016/j.proche.2014.05.011

Wang, H., Deng, T., Wang, Y., Cui, X., Qi, Y., Mu, X., Hou, X., and Zhu, Y. (2013a). "Graphene oxide as a facile acid catalyst for the one-pot conversion of carbohydrates into 5-ethoxymethylfurfural," Green Chem. 15(9), 2379-2383. DOI:

10.1039/C3GC41109E 
Wang, Y., Deng, W., Wang, B., Zhang, Q., Wan, X., Tang, Z., Wang, Y., Zhu, C., Cao, Z., Wang, G., and Wan, H. (2013b). "Chemical synthesis of lactic acid from cellulose catalysed by lead(II) ions in water," Nat. Commun. 4, 2141. DOI:

$10.1038 /$ ncomms 3141

Wang, H., Kong, Q., Wang, Y., Deng, T., Chen, C., Hou, X., and Zhu, Y. (2014).

"Graphene oxide catalyzed dehydration of fructose into 5-hydroxymethylfurfural with isopropanol as cosolvent," ChemCatChem 6(3), 728-732. DOI: $10.1002 /$ cctc. 201301067

Yang, S.-T., Chen, S., Chang, Y., Cao, A., Liu, Y., and Wang, H. (2011). "Removal of methylene blue from aqueous solution by graphene oxide," J. Colloid. Interf. Sci. 359(1), 24-29. DOI: 10.1016/j.jcis.2011.02.064

Yang, L., Su, J., Carl, S., Lynam, J. G., Yang, X., and Lin, H. (2015a). "Catalytic conversion of hemicellulosic biomass to lactic acid in $\mathrm{pH}$ neutral aqueous phase media," Appl. Catal. B-Environ. 162(0), 149-157. DOI: 10.1016/j.apcatb.2014.06.025

Yang, Z., Huang, R., Qi, W., Tong, L., Su, R., and He, Z. (2015b). "Hydrolysis of cellulose by sulfonated magnetic reduced graphene oxide," Chem. Eng. J. 280, 90-98. DOI: 10.1016/j.cej.2015.05.091

Zargari, N., Kim, Y., and Jung, K. W. (2015). "Conversion of saccharides into formic acid using hydrogen peroxide and a recyclable palladium(ii) catalyst in aqueous alkaline media at ambient temperatures," Green Chem. 17(5), 2736-2740. DOI: 10.1039/C4GC02362E

Zhao, G., Ren, X., Gao, X., Tan, X., Li, J., Chen, C., Huang, Y., and Wang, X. (2011). "Removal of $\mathrm{Pb}$ (ii) ions from aqueous solutions on few-layered graphene oxide nanosheets," Dalton Transaction. 40(41), 10945-10952. DOI: 10.1039/C1DT11005E

Zhao, X., Wang, J., Chen, C., Huang, Y., Wang, A., and Zhang, T. (2014). "Graphene oxide for cellulose hydrolysis: How it works as a highly active catalyst?," Chem. Commun. 50(26), 3439-3442. DOI: 10.1039/C3CC49634A

Zhu, S., Wang, J., and Fan, W. (2015). "Graphene-based catalysis for biomass conversion," Catal. Sci. Technol. 5(8), 3845-3858. DOI: 10.1039/C5CY00339C

Article submitted: May 3, 2017; Peer review completed: July 15, 2017; Revised version received: July 21, 2017; Accepted: August 3, 2017; Published: August 14, 2017.

DOI: 10.15376/biores.12.4.7133-7144 